\title{
High precision leveling supporting the International Comparison of Absolute Gravimeters
}

\author{
Z. Jiang ${ }^{1}$, M. Becker ${ }^{2}$, P. Jousset ${ }^{3}$, A. Coulomb ${ }^{4}$, L. Tisserand ${ }^{1}$, P. Boulanger ${ }^{4}$, D. Lequin ${ }^{3}$, F. Lhermitte ${ }^{4}$, J.L. \\ Houillon $^{4}$ and F. Dupont ${ }^{3}$
}

\author{
1 International Bureau of Weights and Measures (BIPM), Pavillon de Breteuil, F-92312, SEVRES CEDEX, France, zjiang@bipm.org \\ 2 Institute of Physical Geodesy, Technische Universität Darmstadt (IPGD), Germany \\ 3 Bureau de Recherches Géologiques et Minières (BRGM), France \\ 4 Institut Géographique National (IGN), France
}

\begin{abstract}
The local gravity field strongly dependents on the vertical terrain deformation. $1 \mathrm{~cm}$ displacement implies about $3 \mu \mathrm{Gal}$ change in the vertical gravity acceleration. The precision of absolute and relative gravimetry nowadays is within $1 \mu \mathrm{Gal}$. High precision leveling is a method indispensable to monitor the benchmark and terrain stability in the BIPM (Bureau International des Poids et Mesures). Associated with the ICAG (International Comparison of Absolute Gravimeters), repeated leveling measurements were carried out in the past decades.
\end{abstract}

In the begining of the century, a strategy was outlined that the ICAG should be upgraded as a metrological Key Comparison of the CIPM (Comité International des Poids et Mesures) under the MRA (Mutual Recognition Arrangement) recognised officially by the designated governmental organizations. The BIPM Site B was then constructed and completed in Spring 2001. The pillar is $4 \times 6 \times 1.5 \mathrm{~m}^{3}$ in dimension and more than 80 tons in weight. Such a huge new built concrete body would produce the local deformation due to its sinking or tilting. This in turn influences the local gravity field. Rigorous levelling measurements were performed by BRGM (Bureau de Recherches Géologiques et Minières, France) since 2001 and repeated together with the 4-year ICAGs of 2001, 2005 and 2009. The ICAG2009 was characterised by being the first CIPM Key Comparison and supporting the BIPM watt balance (WB) project, the pillar of which was built in Spring 2009. The IGN (Institut Géographique National, France) was hence invited to participate in the leveling. The latter measured also the link between the BIPM local net and the external stations of the French national height reference system IGN69.

In this paper, we report the final results of the leveling missions 2001, 2005 and 2009 and compare the results. We investigate the instability of the BIPM gravity-leveling stations. We conclude that the existing and the newbuilt stations can be considered as stable for the purposes of the ICAGs and the WB, although further repeated measurement may be required for the WB site.

For the first time, detailed and complete leveling data and results are published ${ }^{1}$. After 30 years' of organizing and holding eight ICAGs, the BIPM will hand over the KC ICAG2013 to another MRA designated institute. This paper serves also as a technical and historical report of the precision leveling, a sub-task of the ICAGs.

Keywords: Precision leveling, NGF, IGN69, height and height reference system

\section{Notation}

BIPM: Bureau International des Poids et Mesures

BRGM : Bureau de Recherches Géologiques et Minières, France

IGN : Institut Géographique National, France

ICAG: International Comparison of Absolute Gravimeters

KC: CIPM key comparison

WB: BIPM watt balance

$1 \mathbf{G a l}=1 \mathrm{~cm} \mathrm{~s}^{-2}$ (the default unit used in this paper is $\boldsymbol{\mu G a l}$ )

$\boldsymbol{H}$ : height in meters defined in the French national height reference system

\footnotetext{
${ }^{1}$ Only the final result of 2005 leveling mission was published in [4] where, instead of NGF, the height reference system was given to be IGN69. This is not right and will be corrected in this paper.
} 
$\boldsymbol{\delta} \boldsymbol{H}$ : difference of $H$

Mean: mean value of a data set

Std or $\boldsymbol{\sigma}$ : sample standard deviation

\section{Introduction}

In the absolute and relative gravimetry practices, a measured point is defined at a certain distance vertically above the ground benchmark. The free air gravity acceleration is a linear function of the altitude. The coefficient is about $3 \mu \mathrm{Gal} / \mathrm{cm}$. The stability of a local gravity field strongly dependents on the vertical terrain deformation. At present, the precision of state-of-the-art of the absolute and relative gravimetry nowadays approaches $1 \mu \mathrm{Gal}$ $[3,4]$. For most of the geoscience applications, permanent gravity stations are installed in stable locations. As the base of the ICAG (International Comparison of Absolute Gravimeters) and a starting gravity point of certain geoscience organisations, the stability of the BIPM (Bureau International des Poids et Mesures) local gravity field is important. High precision leveling is an effective method to monitor the variation in height of the gravity stations. Associated with the ICAG in the past decades, irregular leveling measurements were performed.

High precision and repeated leveling measurements have been organized since 2001. Then a long-term program of pushing the ICAG towards a metrological Key Comparison (KC) of the CIPM (Comité International des Poids et Mesures) was initiated [1]. The result of a KC under the convention of the MRA (Mutual Recognition Arrangement) is recognised officially by the designated governmental organizations [2]. As a part of the construction of the Pavillon du Mail (PM in Figure 2.1), a new gravity laboratory was built which is a halfburied hall,where the Site B comprises 7 stations (Figure 2.2.1). It was completed in Spring 2001, six months before the ICAG2001. The 7 stations are B, B1, B2, B3, B4, B5 and B6 over the same concrete pillar. B5 and B6 were installed afterwards in 2004 . The pillar is $4 \times 6 \times 1.5 \mathrm{~m}^{3}$ in dimension and more than 80 tones in weight. Such a huge new-built concrete body would produce the local deformation due to its sinking or tilting before its final stabilisation. In addition, the whole building of the Pavillon du Mail, constructed in 2000, may also suffer a period of the settlement and stabilisation. These in turn may affect the local gravity field.

It order to monitor the possible instabilities, rigorous levelling measurements were performed by BRGM (Bureau de Recherches Géologiques et Minières, France) since 2001 associated with the ICAGs held in 2001, 2005 and 2009. The ICAG2009 was characterised by being the first CIPM KC and supporting the new BIPM watt balance (WB) project. The WB laboratory locates in the basement of the Building Observatoire (OBS in Figure 2.1) of which the gravity and WB pillars were built in Spring 2009. The IGN (Institut Géographique National, France), official organization that established and maintains the French national height reference system IGN69, was hence invited to participate in the enforced leveling program. The IGN measured also the link between the BIPM local net and the external IGN69 stations.

In the following discussions, we first in chapter II outline the structure of the BIPM gravity-leveling network and describe the stations. We then introduce the organization of the leveling measurement and the relation between the BIPM local net and the French national height stations. Special attention is given to the evolution of the French height reference systems because of the complexity of the somehow co-existing references in France. In chapter III, we report the final results of the leveling missions 2001, 2005 and 2009. By comparing the results obtained over the last decade, we investigate the stability of the BIPM gravity-leveling stations. We conclude that the existing and the new-built stations are stable for the purposes of the ICAGs and the WB project. However, it is suggested to repeat leveling measurements at least one more time for the WB site.

This is the first time, the detailed and complete leveling data and results are published. After 32 years' organizing and holding the previous eight ICAGs, the BIPM has decided to hand over the KC ICAG2013 to other MRA designated organizations. This paper serves then as a technical and historical document of the previous leveling tasks associated with the so far ICAGs.

\section{The BIPM gravity-levelling network}

\subsection{The gravity-levelling stations}

In the BIPM yard, there are four individual levelling stations: two old national levelling points PBK3-360 and 361 and two new stations PBK3-360a and 361-I established in the 2009 mission by IGN [5-9], cf. Figure 2.1 and Table 3.1.1. As illustrated, there are 18 levelled gravity stations: A, A1, A2, B, B1, B2, B3, B4, B5, B6, C1, C2, 
W1, W2, W11, W14, W15 and W18. C1 and C2 are the out-door stations used as a short calibration baseline for the relative gravimeters. All other stations are indoor.

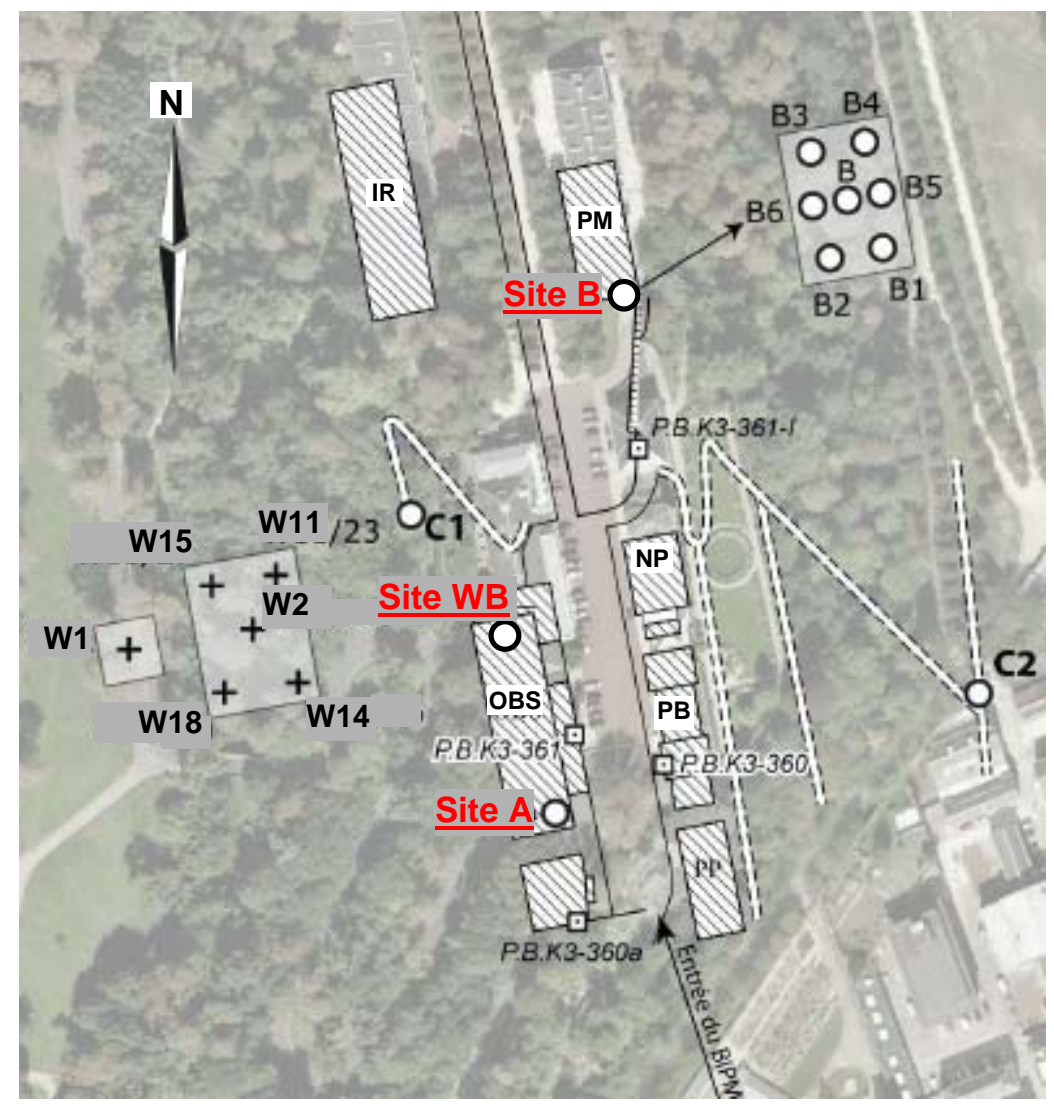

Figure 2.1 The gravity-levelling stations of BIPM.

There are 4 leveling stations: the PBK3-360a and 361-I are the new stations established in the 2009 mission by IGN and the IGN PBK3-360 and 361 are the already existed stations and both are the $4^{\text {th }}$ order stations and have their heights in the ancient and new French height systems: the NGF and the IGN69.

\subsection{Description of the gravity-leveling stations}

\subsubsection{The $B$ and $W B$ sites}

The new building, the Pavillon du Mail, was constructed in 2000. This enabled the extension of the gravityleveling net by creating a number of new stations for the comparisons. The foundation for the new site $\mathrm{B}$ (composed of the stations B, B1, B2, B3, B4 and added in 2004 B5, B6) is a concrete block with a mass of more than 80 tones with the dimensions $6.0 \mathrm{~m}$ in length, $4.0 \mathrm{~m}$ in width and $1.5 \mathrm{~m}$ in depth. The top surface of the foundation is leveled to the floor to minimize the non homogeneity of the gravity field. This construction differs from that of the pillars of sites A and A2 in the Observatoire building. The two pillars on A site (A and A2) have a height of about $2.4 \mathrm{~m}$ above floor level in the basement and would rise the problem of instability. To improve isolation from micro-seismic vibrations, the new foundation is installed on pads of an elastic material inserted between its lower surface and the bottom of the hole in the concrete basement. No metal reinforcing bars were used in the construction of this foundation. Figure 2.2.1 shows the positions of the stations on the site B pillar.

The Site of the WB laboratory is a renovated ancient laboratory located in the basement of the Observatoire building (OBS in Figure 2.1). There are in total two leveled gravity stations (W1 and W2 with permanent benchmarks on the ground) and 4 leveling stations (W11, W14, W15 and W18 without permanent benchmarks). The W1 is in the gravimeter pillar of which the top surface is about $7 \mathrm{~cm}$ lower than surrounding ground surface, cf. Figure 2.2.2. The top surface of the gravity pillar is about $1.54 \mathrm{~m}^{2}$ and that of the WB is about $4.0 \times 2.45 \mathrm{~m}^{2}$. 


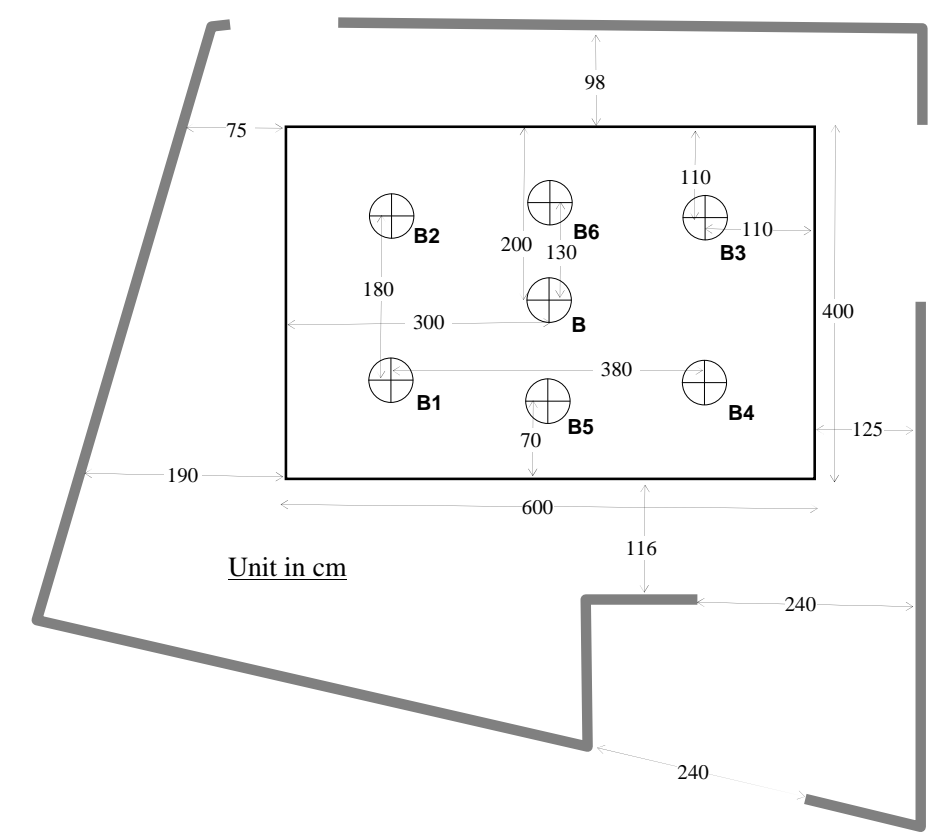

Figure 2.2.1 The gravimetry laboratory and the Site B pillar built in Spring 2001. There are the 7 gravity-leveling stations on the pillar: B, B1-B6 of which the B5 and B6 were installed in 2004 (dimensions in cm). The station locations are symmetric to the B station
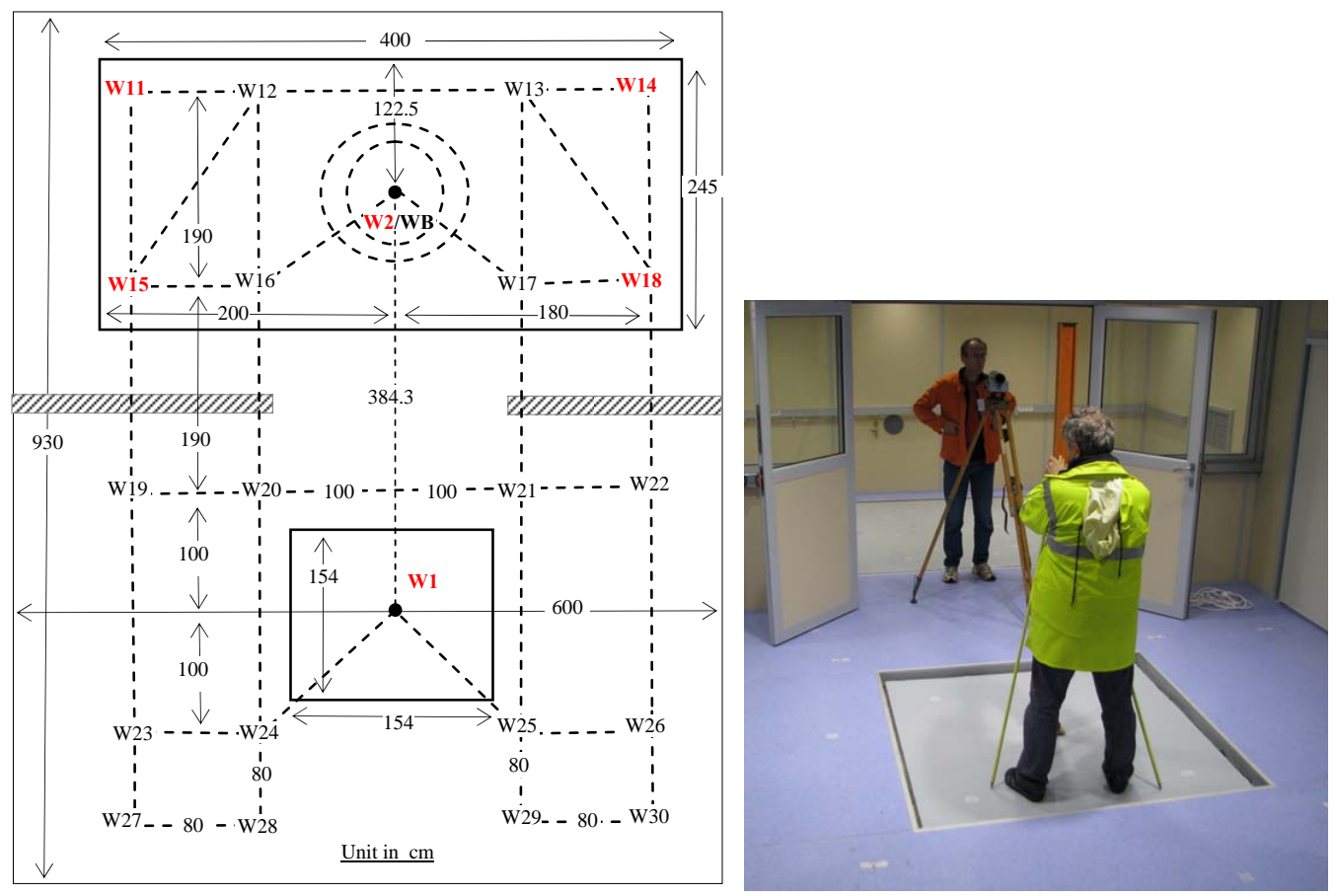

Figure 2.2.2 Site WB and the gravity-stations of which 6 are leveled (W1, W2, W11, W14, W15 and W18). The top surface of the pillar W1 is $7 \mathrm{~cm}$ lower than surrounding ground surface (dimensions in $\mathrm{cm}$ ). A leveling between W1 and W2 is undertaking

\subsubsection{Description of the stations}

There are two kinds of benchmarks on the indoor and outdoor gravity-leveling stations cf. Figure 2.2.3. The outdoor benchmarks made off bronze are buried in the top surfaces of the pillars of C1 and C2. The reference point is defined on the cross centre on the top surface of the benchmark. As for the indoor stations, a disk of $1 \mathrm{~cm}$ in height and $40 \mathrm{~cm}$ in diameter for B, B1, B2, B3 and B4 and of $45 \mathrm{~cm}$ for B5 and B6 are installed. The disk is glued to the ground surface and at the centre is a hole of $5 \mathrm{~cm}$ in diameter. Then a cover covers the hole. Both the disk and the small cover are made from aluminum. The reference point is defined as the cross in the centre on the top surface of the cover which is $1 \mathrm{~mm}$ higher than the top surface of the disk. 

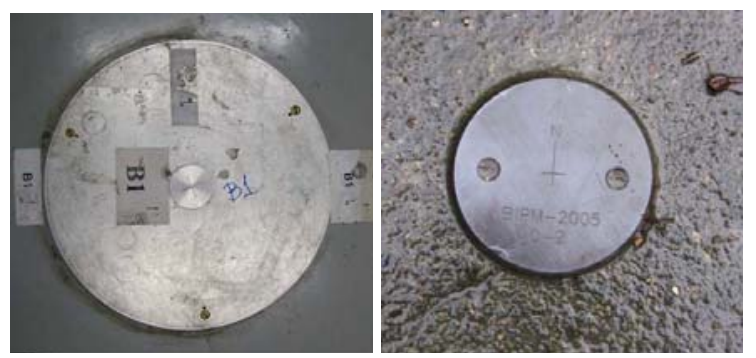

Figure 2.2.3 Two kinds of benchmarks on the indoor (left B1) and the outdoor (right C2) gravity stations

The old national levelling points PBK3-360 and 361 are the in-wall points, See Figures 2.2.4 and 3.2.1. The point PBK3-361 is very stable and is used as the starting point since 2001.

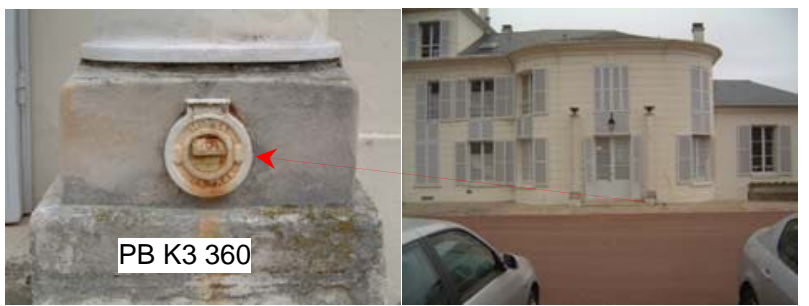

Figure 2.2.4 The NGF-Lallemand leveling point on the wall of the Nouveau Pavillon building of BIPM and is numbered P.B.K3-360 with its value $66.0612 \mathrm{~m}$ in IGN69. The last measurement visit was in 1968 by the IGN. This is the back-up point.

\section{The precision levelling between in 2001, 2005 and 2009}

Repeated precision leveling measurements were carried out three times during the duration of 10 years in 2001, 2005 and 2009. The height results were not computed based on the same height reference systems. In this section, we first investigate the stability of the leveling stations at BIPM and then quickly review the height reference systems in France. We then convert all the results into the current French height system and finally make a comparison of the results to investigate if there were significant terrain deformations during the last decades.

\subsection{Verification of the stability of the leveling stations and the starting values}

The BRGM performed the leveling measurement in Aug. 2009 and the IGN did in Nov.-Dec. 2009. The instruments used were Leica Wild Nak2 automatic level (serial number 456924)and Zeiss Dini 10 (Figure 3.2.1) respectively. Before the mission 2009, the IGN made an investigation in the existing national leveling stations located between $200 \mathrm{~m}$ to $2 \mathrm{~km}$ to check the stabilities of all related stations since the last measurements performed in the 60s' of last century, see Table 3.1.1 and Figure 3.1.1. An iteration of pre-adjustment was carried out to take out the unstable stations. A known station is considered stable if the difference of the heights between the known and the new value is, according to the French regulations, less than $0.7 \mathrm{~mm} \times(1+n)$ for the first order and $1.0 \mathrm{~mm} \times(1+n)$ for other orders. Here the $n$ is the number of intermediate measuring points along the leveling line. Only the stable stations will be used as starting values. In total 10 stations were measured and four of them (italic letters in Table 3.1.1) were stable, including the P.B.K3-361 which was used as the starting point by BRGM since 2001. For this particular point, as given in Table 3.1.1, the difference between the previous measurement in 1968 and the new one is only $2.2 \mathrm{~mm}$, which can be considered as height variation during the 41 years or simply the measurement errors. While that of the P.B.K3-360 is $6.6 \mathrm{~mm}$. In addition, three new stations were established and two of them are in BIPM: P.B.K3-360a and P.B.K3-361-I (Figure 2.1). 


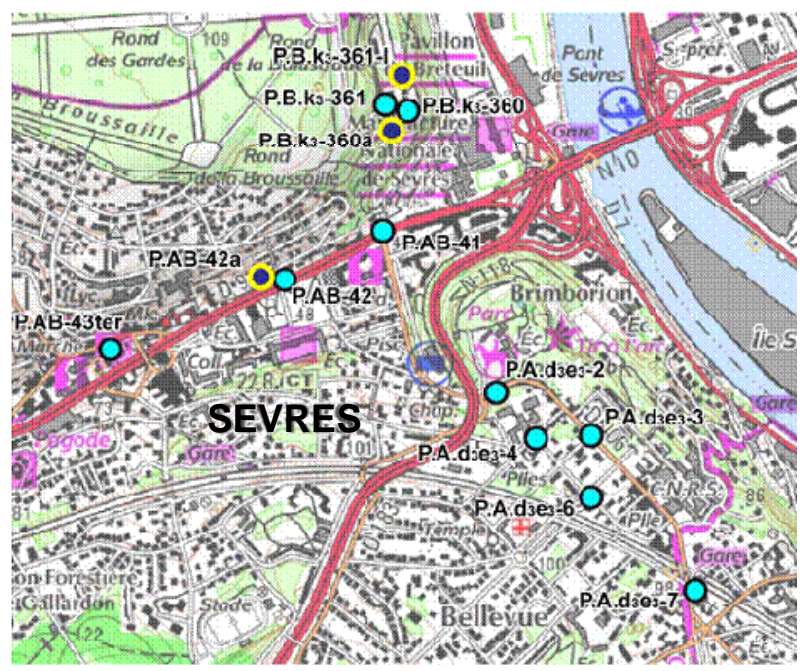

Figure 3.1.1 The investigated national levelling stations within $2 \mathrm{~km}$ from the BIPM in the IGN 2009 mission

Table 3.1.1 The near-by national leveling stations and the heights measured in different periods.

$H_{2009}$ is the results obtained in the IGN 2009 mission, $H_{\text {old }}$ is the result of the existing IGN69 stations. The italic values are the starting values for the computation of the IGN 2009 mission and the P.B.K3-361 is the starting point of the BRGM leveling missions in 2001, 2005 and 2009

\begin{tabular}{|c|c|c|c|c|c|c|c|}
\hline Stn & $\begin{array}{l}\text { Latitude } \\
\circ \quad, \quad "\end{array}$ & $\begin{array}{c}\text { Longitude } \\
\end{array}$ & order & Year & $\begin{array}{c}H_{\text {old }} \\
/ \mathrm{m}\end{array}$ & $\begin{array}{c}H_{2009} \\
/ \mathrm{m}\end{array}$ & $\begin{array}{c}H_{\text {old }}-H_{2009} \\
/ \mathrm{m}\end{array}$ \\
\hline P.A.D3E3-7 & 21347 & 484902 & 3 & 1968 & 99.0252 & 99.0230 & 0.0022 \\
\hline P.A.D3E3-6 & 21334 & 484915 & 3 & 1968 & 90.1337 & 90.1344 & -0.0007 \\
\hline P.A.D3E3-4 & 21328 & 484919 & 3 & 1968 & 87.1684 & 87.1542 & 0.0142 \\
\hline P.A.D3E3-3 & 21335 & 484920 & 3 & 1968 & 88.0659 & 88.0595 & 0.0064 \\
\hline P.A.D3E3-2 & 21323 & 484923 & 3 & 1968 & 77.9886 & 77.9878 & 0.0008 \\
\hline P.AB-41 & 21310 & 484 & 2 & 1968 & 39.0762 & 39.0601 & 0.0161 \\
\hline P.AB-42 & 21258 & 484 & 2 & 1968 & 45.8741 & 45.8523 & 0.0218 \\
\hline P.AB-42a & 21258 & 484932 & 2 & 2009 & - & 45.8491 & - \\
\hline P.AB-43ter & 21237 & 484926 & 2 & 1985 & 49.7330 & 49.7217 & 0.0113 \\
\hline P.B.K3-360 & 21312 & 484945 & 4 & 1968 & 66.0678 & 66.0612 & 0.0066 \\
\hline P.B.K3-360a & 21311 & 484944 & 4 & 2009 & - & 65.4921 & - \\
\hline P.B.K3-361 & 21311 & 484946 & 4 & 1968 & 66.4536 & 66.4558 & -0.0022 \\
\hline P.B.K3-361-I & 21312 & 484948 & 4 & 2009 & - & 62.7857 & - \\
\hline & & & & & & \multicolumn{2}{|c|}{ Mean : 0.0077} \\
\hline & & & & & & Std : & \pm 0.0080 \\
\hline
\end{tabular}

\subsection{The French height reference systems and their interrelation}

Special attention is paid to the evolution of the French national height reference systems. They are somehow coexist and used by different organizations in France. Users may be confused by the complexity and errors are likely to occur as in the ICAG 2005 height analysis earlier ${ }^{2}$.

The first leveling network was designed and measured under the direction of Adrien Bourdalouë from 1857 to 1864. The second one was the so called NGF-Lallemand (Nivellement Général de la France or French general leveling in English) by Charles Lallemand started in 1884 based on the macrograph recording of Marseille from the 1 Feb. 1885 to 1 Jan. 1897. The orthometric height system with theoretical gravity correction was adopted. The NGF was largely used in France for about a century. The BRGM performed the leveling measurements in 2001, 2005 and 2009 and the height results were given in the NGF. The starting value used by BRGM was that marked on the benchmark: 66.12 m, as illustrated in Figure 3.2.1. From 1962 to 1969, the IGN upgraded the

\footnotetext{
${ }^{2}$ Remark: in an earlier publications [4] for the ICAG2005, the height reference should be the NGF but miswritten as IGN69.
} 
NGF network by converting it to the normal height system using measured gravity values. The new system is named NGF-IGN 1969 or IGN69. The leveling measured and computed by IGN in 2009 is given in the IGN69. The IGN69 is 30 to $60 \mathrm{~cm}$ over the NGF in France and is about $33 \mathrm{~cm}$ in the Paris region.

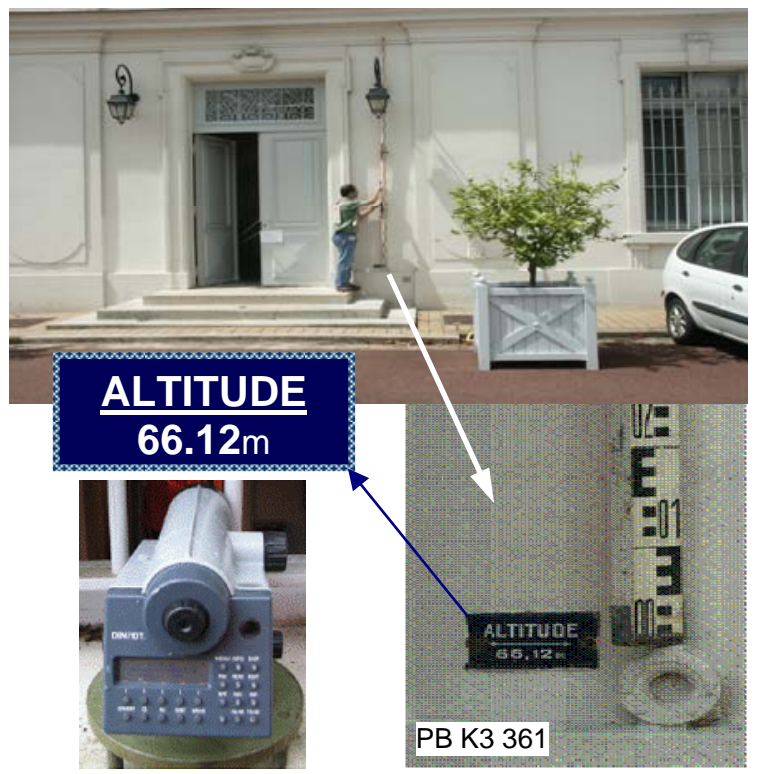

Figure 3.2.1 The NGF leveling point on the wall of the Observatoire building of BIPM and its value 66.12m in the NGF served as the starting value of the height measurement before the RGC2009. The same point in the new IGN system is numbered P.B.K3-361 with its value $66.4558 \mathrm{~m}$ in IGN69. The difference between the two systems is: IGN69-NGF=+0.3358m. The levelling instrument used by IGN was the Zeiss Dini 10

\subsection{The repeated height measurement results between 2001 and 2009}

Since the ICAG2001, the precision leveling has been carried out by BRGM. Only the inner-stations in BIPM were leveled without linking them to the external leveling stations. The starting point and starting value are as illustrated in Figure 3.2.1. The NGF-Lallemand leveling point is installed on the façade wall of the Observatoire building of BIPM and its value is $66.12 \mathrm{~m}$ in NGF served as the starting value of the height measurement before the RGC2009. The same point in the IGN system is numbered P.B.K3-361 with its normal height value $66.4558 \mathrm{~m}$ in IGN69. The difference between the two systems on this point is: IGN69-NGF $=0.3358 \mathrm{~m}$, noting that the orthometric height in NGF is rounded off to $\mathrm{cm}$. A back up point is shown in Figure 2.2.4 numbered as P.B.K3-360 and the normal height is $66.0612 \mathrm{~m}$ in IGN69.

Table 3.3.1 gives the height results of the repeated measurements performed by BRGM in 2001, 2005 and 2009 as well as the differences between the heights during the 10 years. The difference between 2001 and 2005 is only about $+1 \mathrm{~mm}$, within the measurement uncertainty. However, the heights of 2009 are 3 to $5 \mathrm{~mm}$ lower than those of 2005 and 2 to $3 \mathrm{~mm}$ lower than those of 2001. At present, we have no exact explanation for this height changes. Because the discrepancies are either all positive or all negative, the major part comes likely from the change of the height difference between the pillar B and the starting point: P.B.K3-361. Most probably, there was a subsidence of the pillar B because P.B.K3-361 is installed in a wall built in 1878 and considered stable by the IGN investigation, $2.2 \mathrm{~mm}$ different from the last measurement in 1968. We can almost exclude the usual causes of the deformation: such as the influences of the seasonal variations of temperature and humidity on the wall and foundation of the Observatory. However it was mentioned that, the benchmark of P.B.K3-361 was painted during a façade renovation of the Observatory before 2001. The thickness of the extra material would make the 2001 starting value higher than the true. The coating layer, as can be seen even now some millimeters in thick, was removed later. This would make the 2005 starting value lower than that of the 2001's and compensate the subsidence of pillar B during 2001 to 2005. Unfortunately, we have not exact information now to allow a reliable conclusion. Nevertheless, $3 \mathrm{~mm}$ implies a change of $0.9 \mu \mathrm{Gal}$ in gravity which is lower than the repeatability of the gravimetry measurement between the ICAGs due to the measurement uncertainties between the site A and site B. On the other side, the in-door stations on the pillar site B can be considered as stable with respect to each other, only variations of $1 \mathrm{~mm}$ within the uncertainty of the leveling measurements. Therefore, the observed height changes should not disturb the relative and absolute gravity difference results on the B site which was the major location performing the ICAGs. An exception is the difference of the - $18 \mathrm{~mm}$ of 20092005 for the station C2. As seen in Figure 2.1, C2 is far from the main part of the net and about 20 meter lower 
than the station B. The access is difficult especially when it rains. This was the case of the measurements of 2009. The fact that the $\mathrm{C} 2$ pillar was built in the soil surrounding by the huge trees made it unstable. From the Table 3.1.1, even some $2^{\text {nd }}$ order stations have changed about $2 \mathrm{~cm}$. The back up leveling point P.B.K3-360 was not used for the BRGM measurements.

Table 3.3.1 Repeated leveling measurement results during 10 years by BRGM with the inter-comparisons (Heights are given in NGF reference system)

\begin{tabular}{|c|r|r|r|r|r|r|}
\hline \multirow{2}{*}{ Station } & \multicolumn{2}{|c|}{$\boldsymbol{H}$ in NGF / } & \multicolumn{3}{c|}{ Difference of $\boldsymbol{H} \mathbf{m}$} \\
\cline { 2 - 8 } & $\mathbf{2 0 0 1}$ & $\mathbf{2 0 0 5}$ & $\mathbf{2 0 0 9}$ & $\mathbf{2 0 0 5 - 2 0 0 1}$ & $\mathbf{2 0 0 9 - 2 0 0 5}$ & $\mathbf{2 0 0 9 - 2 0 0 1}$ \\
\hline A & 65.938 & 65.939 & 65.937 & 0.001 & -0.002 & -0.001 \\
\hline A1 & & 65.941 & & & & \\
\hline A2 & 65.956 & 65.957 & & 0.001 & & \\
\hline B & 56.327 & 56.329 & 56.324 & 0.002 & -0.005 & -0.003 \\
\hline B1 & 56.341 & 56.342 & 56.338 & 0.001 & -0.004 & -0.003 \\
\hline B2 & 56.339 & 56.34 & 56.337 & 0.001 & -0.003 & -0.002 \\
\hline B3 & 56.334 & 56.335 & 56.332 & 0.001 & -0.003 & -0.002 \\
\hline B4 & 56.329 & 56.33 & 56.326 & 0.001 & -0.004 & -0.003 \\
\hline B5 & & 56.329 & 56.326 & & -0.003 & \\
\hline B6 & & 56.335 & 56.331 & & -0.004 & \\
\hline C1 & & 76.457 & 76.459 & & 0.002 & \\
\hline C2 & & 37.64 & 37.622 & & -0.018 & \\
\hline W1/13 & & & 62.77 & & & \\
\hline W2/14 & & & 62.838 & & & \\
\hline
\end{tabular}

Table 3.3.2 Repeated leveling measurement results by BRGM and that of the IGN 2009 mission (Heights are given in the IGN69 reference system)

\begin{tabular}{|c|r|r|r|r|r|}
\hline & \multicolumn{2}{|c|}{$\boldsymbol{H}$ by BRGM in IGN69 } & $\begin{array}{c}\text { H by IGN } \\
\text { / } \mathrm{m}\end{array}$ & $\begin{array}{c}\text { BRGM - IGN } \\
\text { / m }\end{array}$ \\
\cline { 2 - 6 } Station & $\mathbf{2 0 0 1}$ & $\mathbf{2 0 0 5}$ & $\mathbf{2 0 0 9}$ & $\mathbf{2 0 0 9}$ & $\mathbf{2 0 0 9}$ \\
\hline A & 66.2738 & 66.2748 & 66.2728 & 66.2722 & 0.0006 \\
\hline A1 & & 66.2768 & & & \\
\hline A2 & 66.2918 & 66.2928 & & & \\
\hline B & 56.6628 & 56.6648 & 56.6598 & 56.6584 & 0.0014 \\
\hline B1 & 56.6768 & 56.6778 & 56.6738 & 56.6723 & 0.0015 \\
\hline B2 & 56.6748 & 56.6758 & 56.6728 & 56.6705 & 0.0023 \\
\hline B3 & 56.6698 & 56.6708 & 56.6678 & 56.6654 & 0.0024 \\
\hline B4 & 56.6648 & 56.6658 & 56.6618 & 56.6597 & 0.0021 \\
\hline B5 & & 56.6648 & 56.6618 & 56.6592 & 0.0026 \\
\hline B6 & & 56.6708 & 56.6668 & 56.6649 & 0.0019 \\
\hline C1 & & 76.7928 & 76.7948 & 76.7956 & -0.0008 \\
\hline C2 & & 37.9758 & 37.9578 & 37.9535 & 0.0043 \\
\hline W1/13 & & & 63.1058 & 63.1079 & -0.0021 \\
\hline W2/14 & & & 63.1738 & 63.1770 & -0.0032 \\
\hline W11/23 & & & & 63.1749 & \\
\hline W14/26 & & & & 63.1737 & \\
\hline W15/27 & & & & 63.1767 & \\
\hline W18/30 & & & & 63.1737 & \\
\hline
\end{tabular}

Preparing the RGC2009, we realized that the significant difference of nearly $30 \mathrm{~cm}$ between the NGF and the IGN69. We then invited the IGN, official responsible of the height reference system in France, to make an investigation in the starting point and the corresponding values used for the earlier ICAGs/RGCs. The task was fulfilled in Dec. 2009 [5]. Some 13 national graded points within a 2 kilometer diameter zone around BIPM were carefully investigated and 4 stable points, including the point P.B.K3-361, were selected as the starting points of 
the adjustment of the IGN leveling measurements. Table 3.3.2 lists all the height results given by missions of BRGM and IGN in the IGN69 reference system. Here the orthometric height values in NGF have been converted to the normal heights in IGN69 system, by adding the constant offset of $0.3358 \mathrm{~m}$ computed from the height values of the only IGN-BRGM-common-point P.B.K3-361. The last column of the table gives the differences of the two sets of the results. As seen, on the 8 common stations of the sites A and B, the heights of the BRGM are constantly about $2 \mathrm{~mm}$ higher than IGN's. However for the difference on the two WB stations, BRGM's are lower than that of IGN's by $2.5 \mathrm{~mm}$. This would be caused by the measurement methods. The WB site is located in the basement of the Observatoire. The accessibility is rather difficult. BRGM performed a leveling profile through the stairs which are narrow and deep. But IGN performed a direct profile going through a little window of the basement. The latter seems a less disturbed operation. The difference of the height measurements for outdoor point C2 is $4.3 \mathrm{~mm}$ that may be caused by the difficult condition as discussed above.

\subsection{The relief of the surfaces of the pillar $B$ and the pillar WB}

The top surfaces of the pillars of the sites B and WB are $4 \times 6 \mathrm{~m}^{2}$ and $2.5 \times 4 \mathrm{~m}^{2}$ respectively. It is interesting to point out that the surface of the WB pillar seems smoother than that of B pillar, see Figure 3.3.1. The maximum differences in heights are for $B$ pillar $B 1-B=1.39 \mathrm{~cm}$ while for $\mathrm{WB}$ pillar $\mathrm{W} 2-\mathrm{W} 14=0.33 \mathrm{~cm}$, noting also that the WB pillar is smaller than the B pillar. By Figure 3.3.1, the contour map of B site illustrates a 'valley' from B to the mid-point of B4-B5. We cannot exclude the possibility that the B4 corner sunk about $1 \mathrm{~cm}$, i.e. the pillar sloped down from the B1-B2 edge towards the corner of B4 after its construction. From the Table 3.3.1, the height variations of 2009-2005 and 2009-2001 are $-5 \mathrm{~mm}$ and $-3 \mathrm{~mm}$ at the B station and that of B4 are $-4 \mathrm{~mm}$ and $-3 \mathrm{~mm}$. However, from the same table, the B4 in 2001 was already lower $10 \mathrm{~mm}$ than B2 and $12 \mathrm{~mm}$ than B1. This sloping would happen either just after its construction before the leveling measurement in 2001 or due to the construction fault. Table 3.3.1 is based on the measurements of the BGRM and Figure 3.3.1 is base on that of the IGN.
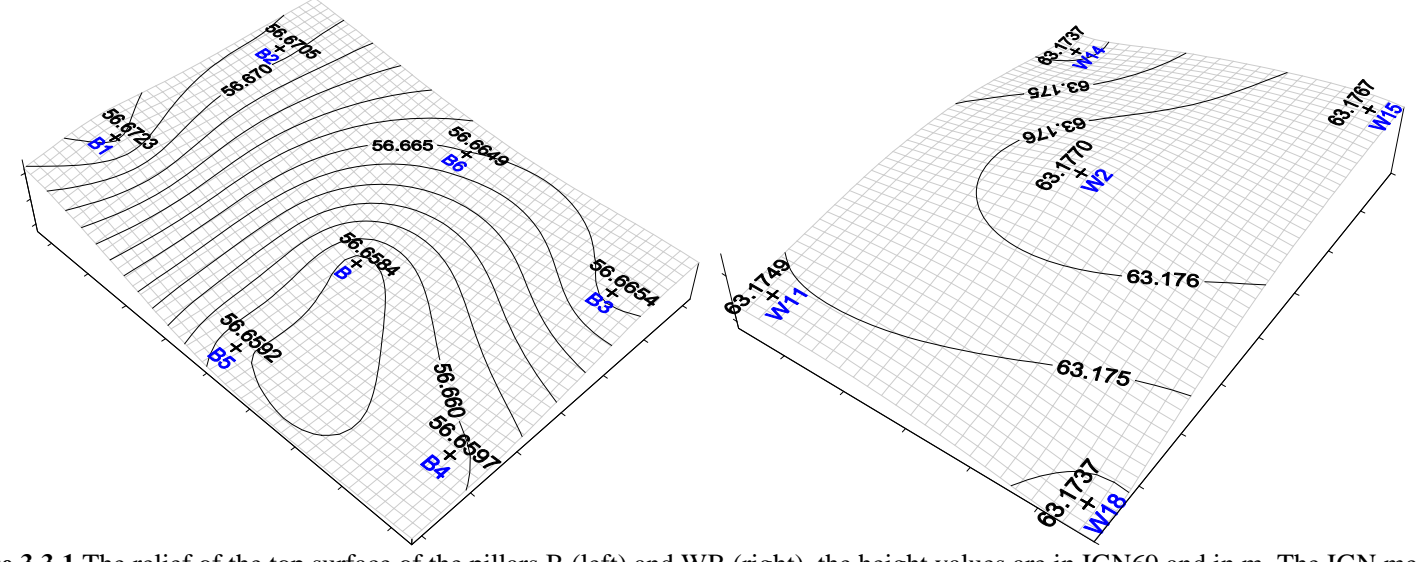

Figure 3.3.1 The relief of the top surface of the pillars B (left) and WB (right), the height values are in IGN69 and in m. The IGN measured normal height values are demonstrated.

\section{Conclusions}

Associated with the ICAGs, precision levelling missions were organised to check the stability in the gravitylevelling stations at the BIPM. To monitor the possible deformation of the site B located in the building Pavillion du Mail constructed in 2000, rigorous levelling measurements have being carried out since 2001. To better support the first ICAG2009 as a CIPM Key Comparison and the BIPM watt balance project of which the pillars were built in 2009, both BRGM and IGN performed the levelling 2009. During the 2009 mission, the BIPM local stations were linked to the French national levelling stations outside of BIPM. The measurement uncertainty is about $2 \mathrm{~mm}$.

Careful comparisons were made between these results. It is concluded that between 2001 and 2009 no deformations in height significantly beyond the repeatability of the gravity measurements (about $2 \mu \mathrm{Gal}$ ) have been confirmed on the B and A sites, which were occupied by the absolute gravimeters during the ICAGs. It is therefore expected that the WB site be stable for the watt balance performance although it is suggested to perform at least one more levelling measurements when possible. 


\section{Acknowledgments}

We thank the BIPM administration, whose support was important to fulfil all the leveling measurements. We are grateful to Mr. R. Sitton for his helpful comments and careful corrections of the English text and the reviewers for their constructive scientific suggestions.

\section{Reference}

[1] BIPM, Technical Protocol of the $8^{\text {th }}$ International Comparison of Absolute Gravimeters ICAG-2009, ftp://tai.bipm.org/ICAG/TP ICAG_2009 Drft 4 1 1.doc

[2] CIPM MRA Key Comparison CCM.G-K1,

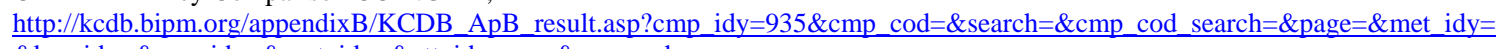
\&bra_idy=\&epo_idy=\&cmt_idy=\&ett_idy_org=\&cou_cod=

[3] Vitushkin L, Becker M, Jiang Z, Francis O, van Dam T M, Faller J, Chartier J-M, Amalvict M, Bonvalot S, Debeglia N, Desogus S, Diament M, Dupont F, Falk R, Gabalda G, Gagnon C G L, Gattacceca T, Germak A, Hinderer J, Jamet O, Jeffries G, Käker R, Kopaev A, Liard J, Lindau A, Longuevergne L, Luck B, Maderasl E N, Mäkinen J, Meurers B, Mizushima S, Mrlina J, Newell D, Origlia C, Pujol E R, Reinhold A, Richard Ph, Robinson I A, Ruess D, Thies S, van Camp M, van Ruymbeke M, de Villalta Compagni M F and Williams S (2002) Results of the Sixth International Comparison of Absolute Gravimeters ICAG-2001 Metrologia 39, 407-24

[4] Jiang Z, Becker M, Francis O, Germak A, Palinkas V, Jousset P, Kostelecky J, Dupont F, Lee C W, Tsai C L, Falk R, Wilmes H, Kopaev A, Ruess D, Ullrich M C, Meurers B, Mrlina J, Deroussi S, Métivier L, Pajot G, Pereira Dos Santos F, Ruymbeke M van, Naslin S and Ferry M (2009) Relative Gravity Measurement Campaign during the 7th International Comparison of Absolute Gravimeters (2005) Metrologia 46, 214-226

[5] BOULANGER P.2009 Opération de nivellement au Bureau des Poids et Mesures (BIPM), SERVICE DE GEODESIE ET DE NIVELLEMENT, Institut Géographique National, COMPTE RENDU CR/G 257, novembre-décembre 2009, ftp://tai.bipm.org/ICAG/2009/RGC/Levelling/

[6] http://geodesie.ign.fr/fiches/pdf/P.B.K3-360a_527544.pdf

[7] http://geodesie.ign.fr/fiches/pdf/P.B.K3-360_496413.pdf

[8] http://geodesie.ign.fr/fiches/pdf/P.B.K3-361 496414.pdf

[9] http://geodesie.ign.fr/fiches/pdf/P.B.K3-361-I 527543.pdf 